\title{
Immunological defects in mice with a targeted disruption in Bcl-3
}

\author{
Edward M. Schwarz, ${ }^{1,3}$ Paul Krimpenfort, ${ }^{2,3}$ Anton Berns, ${ }^{2}$ and Inder M. Verma ${ }^{1,4}$ \\ ${ }^{1}$ Laboratory of Genetics, The Salk Institute, San Diego, California 92186-5800 USA; ${ }^{2}$ Division of Molecular Genetics, The \\ Netherlands Cancer Institute, Amsterdam, The Netherlands
}

\begin{abstract}
The proto-oncogene $b c l-3$ is a member of the IKB family. The Bcl-3 protein is known to interact specifically with the p50 and p52 subunits of NFkB. However, the function of this interaction is not well understood. To determine the in vivo role of Bcl-3, mice were generated that lack the $b c l-3$ gene, Bcl $3(-/-)$. Here we report that Bcl $3(-/-)$ mice appear developmentally normal, but exhibit severe defects in humoral immune responses and protection from in vivo pathogenic challenges. Relative to wild-type mice, Bcl $3(-/-)$ mice are unable to clear $L$. monocytogenes and are more susceptible to infection with $S$. pneumoniae. This phenotype is similar to that observed in the p50(-/ -$)$ mice and the cross between the $\mathrm{Bcl}-3(-/-)$ and $\mathrm{p} 50(-/-)$ mice generates animals with an enhanced phenotype. In accordance with the observed defects in their immune response, the Bcl 3(-/-) mice have normal immunoglobulin levels before and after immunization, but fail to produce antigen-specific antibodies. Additionally, spleens from Bcl-3(-/-) mice are abnormal and void of germinal centers. In contrast, the $\mathrm{p} 50(-/-)$ mice have normal germinal centers. We propose that in in vivo, Bcl-3 can function independently of $\mathrm{p} 50$.
\end{abstract}

[Key Words: Gene targeting; immune deficiency; NF-кB/IкB; pathogenesis; germinal centers]

Received August 16, 1996; revised version accepted December 3, 1996

The Bcl-3 gene was originally identified as a putative proto-oncogene because of its location at the breakpoint junction in the $t(14 ; 19)$ translocation observed in human B-cell chronic lymphocytic leukemia (CLL) (Ohno et al 1990|. Bcl-3 belongs to the IкB family of proteins. It contains a proline-rich amino terminus, a series of seven tandem ankyrin repeats, characteristic of all IкB family members, and a proline- and serine-rich carboxyl terminus. Bcl-3 interacts specifically with the p50 and p52 subunits of NF-kB (Franzoso et al. 1992,1993; Hatada et al. 1992; Kerr et al. 1992; Wulczyn et al. 1992; Inoue et al. 1993; Naumann et al. 1993; Nolan et al. 1993). Based on its structure and association with NF-kB, Bcl-3 has been designated as a member of the I $\mathrm{B}$ family. However, its in vivo function remains poorly understood (Lenardo and Siebenlist 1994; Miyamoto and Verma 1995; Verma et al. 1995). Contrasting reports demonstrate that Bcl-3 retains p50 in the cytoplasm (Naumann et al. 1993) or is transported to the nucleus via association with p50 (Nolan et al. 1993). Additionally, it has been shown that Bcl-3 can prevent, as well as remove, p50 and p52 from binding DNA (Nolan et al. 1993). This inhibitory activity of Bcl-3 requires phosphorylation (Nolan et al. 1993). However,

\footnotetext{
${ }^{3}$ These authors contributed equally to this work.

${ }^{4}$ Corresponding author.

E-MAIL Inder_Verma@qm.salk.edu; FAX (619) 558-7454.
}

Caamano et al. (1996) have generated transgenic mice with constitutive expression of Bcl-3 in thymocytes. Extracts of thymocytes from these mice have enhanced $\mathrm{p} 50$ DNA binding that is phosphorylation dependent.

The question remains, does Bcl-3 act negatively or positively on transcription? Transiently expressed Bcl-3 negatively effects expression of NF- $\mathrm{BB}$-dependent reporter constructs. This inhibitory effect is dose dependent (Kerr et al. 1992). Others argue that Bcl-3 acts positively toward NF-KB-mediated transcription. It has been shown that Bcl-3 can facilitate NF- $\mathrm{B}$ mediated transactivation by removing inhibiting $\mathrm{p} 50$ homodimers from select $\kappa \mathrm{B}$ sites (Franzoso et al. 1992). Additionally, it has been shown that Bcl-3 trans-activates directly through $\kappa \mathrm{B}$ motifs via association with p52 (Bours et al. 1993). Fujita et al. (1993) also demonstrated that Bcl-3 can act as a transcriptional coactivator that activates through NF$\kappa \mathrm{B}$ p 50 homodimers.

In an effort to develop an understanding of the physiological roles of $\mathrm{Bcl}-3$, we have generated mice lacking bcl-3 through embryonic gene targeting. Our results indicate that Bcl-3 does not have a developmental role for immune cells (or other cells), but is required for the generation of normal germinal centers. The Bcl-3(-/ $-\mid$ mice (1) fail to produce antigen-specific antibodies; (2) are unable to clear Listeria monocytogenes; and (3) are more susceptible to infection with Streptococcus pneumoniae. 


\section{Results}

\section{Generation of bcl-3 null mice}

To use homologous recombination to generate a mouse lacking the $b c l-3$ gene, genomic $b c l-3$ DNA was obtained. A genomic 129/SV library was screened using the mouse $b c 1-3$ cDNA as a probe and three recombinant phages were recovered that overlapped a region of $25 \mathrm{~kb}$. This region contains $15 \mathrm{~kb}$ of structural information and includes all nine exons of the $b c l-3$ gene. From these genomic clones, a targeting construct was generated. Internal sequences from a SacII site in exon 1, up to a NotI site, at the beginning of exon 6 were deleted and replaced with the hygromycin resistance gene (Fig. 1A). Homologous recombination of this targeting construct in embryonic stem (ES) cells replaces $\sim 10 \mathrm{~kb}$ of genomic DNA that deletes the coding sequence for five ankyrin repeats of the Bcl-3 protein.

The targeting construct was introduced into E14 ES cells by electroporation (Hooper et al. 1987). Homologous recombination between the targeting construct and the wild-type gene, produces a disrupted gene with diagnostic EcoRI sites. To detect disruption of the $b c l-3$ gene, DNA from either wild-type or targeted ES cells was digested with EcoRI and fractionated by electrophoresis for Southern blot analysis. The fractionated DNA was probed with sequences complementary to the promoter region (probe A). The probe detected diagnostic fragments of 10.5 and $7.5 \mathrm{~kb}$ for the wild-type and mutated bcl-3 alleles, respectively (Fig. 1B). Additionally, the hy- gromycin gene (probe B) hybridized to the $7.5-\mathrm{kb}$ EcoRI fragment of the targeted locus (data not shown). Disruption of the $b c l-3$ gene occurred at a frequency of three in 180 hygromycin resistant clones.

Two targeted ES clones of normal morphology and karyotype were injected into B6 blastocysts and implanted into surrogate mothers. Chimeric male progeny were crossed to FVB/ $\mathrm{N}$ females and germ-line transmission of the disrupted $b c l-3$ gene was obtained (Fig. 1C). Intercrosses between heterozygous animals produced progeny with normal Mendelian transmission of the disrupted $b c l-3$ allele. $b c l-3$ mutant heterozygous or homozygous mice did not show any gross abnormalities as determined by a detailed histopathological analysis of the mice.

To verify that the gene disruption created a null mutation, we examined Bcl-3 expression in spleen (Fig. 1D). $\mathrm{Bcl}-3$ protein was detected in splenocyte extracts from wild-type mice. Extracts from Bcl-3(-/-) mice lacked detectable levels of Bcl-3 protein. Heterozygous mice expressed half as much Bcl-3 protein as wild-type mice. These results indicate that $\mathrm{Bcl}-3$ has been functionally inactivated in homozygous mice.

Expression of $I \kappa B$ and $N F-\kappa B$ family members in the Bcl-3(-/-) mouse is unchanged

Consistent with the findings on studies with the p50, p65, c-Rel, RelB, and IкB $\alpha$ knockout mice (Beg et al. 1995a,b; Kontgen et al. 1995; Sha et al. 1995; Welh et al.
Figure 1. Production of mice lacking bcl-3. (A) Strategy for the disruption of the $b c l-3$ gene. The top line represents the region cloned in $\lambda$ FixII phages; the middle line shows roughly the organization of the $b c l-3$ locus. Boxes represent exons, hatched boxes represent ankyrin repeat encoding exons. Bottom line schematically shows the targeting fragment; below is indicated the sizes of the EcoRI fragments detected by probe $A$ of the wild-type $b c l-3$ and the mutated $b c l-3$ allele. Restriction sites: (RI) EcoRI; (BII) BgIII; (SII) SacII; (Not) Not; (hyg) hygromycin resistance expression cassette. $(B)$ Southern blot analysis of E14 ES cell and clone 205 DNA; DNA was digested with EcoRI and run over a $0.6 \%$ agarose gel; after blotting, the DNA was hybridized with probe A; (size markers): $\lambda$ HindIII; (arrowheads) wild-type and mutant $b c l-3$ allele, $(C)$ Southern blot analysis of DNA isolated from the tail of progeny derived from intercrosses of $B c l-3(+|-|$ animals, DNA was digested with EcoRI and run over a $0.6 \%$ agarose gel. After blotting, DNA was hybridized with probe $A_{\text {; }}$ (size markers): $\lambda$ HindIII. (D) Western blot analysis of spleen lysates from mice genotyped as wild type, heterozygous, and homozygous for the disrupted $b c 1-3$ allele. The protein blot was incubated with serum specific to mouse Bcl-3. Location of specific Bcl-3 bands are indicated; (size marker) prestained size markers (GIBCO, BRL).


B

D

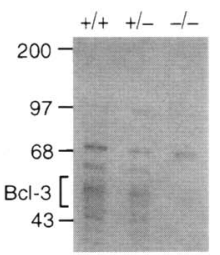

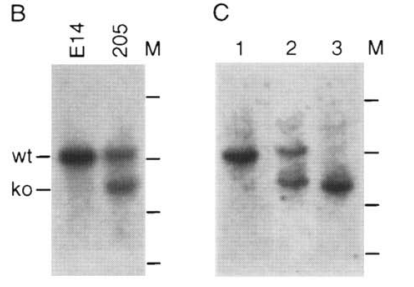


1995|, there is no compensation or altered gene expression of any of the IкB or NF- $\kappa B$ family members in the Bcl-3(-/-) mice. A Western blot of splenocyte extracts shows that the protein levels of $\mathrm{I} \kappa \mathrm{B} \alpha, \mathrm{I} \kappa \mathrm{B} \beta, \mathrm{p} 50$, p52, p65, and $c-$ Rel are equivalent in wild-type, heterozygous, and Bcl-3(-/-) mice (Fig. 2A). To determine if $I_{\kappa} B$ and NF- $\kappa$ B activities were effected in Bcl-3/-|-| mice, we tested the induction of NF- $\mathrm{kB}$ in primary lymphocytes. Purified B cells and $\mathrm{T}$ cells, obtained by fluorescent activated cell sorting (FACS), were stimulated in vitro with phorbol 12-myristate 13-acetate (PMA) and ionomycin for various times. Nuclear extracts were made from these cells. To control for extract integrity, the DNA binding of constitutive Oct l was examined by electrophoretic mobility shift assays (EMSA) with an Oct 1-binding site probe (Fig. 2B). The DNA binding activity of NF- $\mathrm{KB}$ proteins in the extracts was tested in electrophoretic mobility shift assays (EMSA) (Fig. 3). The kinetics of the inducible gel shift are identical in wild-type and Bcl-3/-/-) extracts. To test the integrity of the extracts we examined the constitutive Octl gel shift as a control. We also tested the induction of NF- $\mathrm{kB}$ in primary splenocytes stimulated with lipopolysaccharide (LPS) and tumor necrosis factor- $\alpha(T N F \alpha)$. Again, no differences were observed (data not shown). The composition of the DNA-binding complexes was determined by addition of antiserum specific for various NF- $\mathrm{kB}$ proteins to the extracts before the addition of the probe. One representative experiment is shown (Fig. 2C). The NF-кB DNA complexes of Bcl-3 $(-\mid-)$ extracts did not vary consistently from those of the wild type. Therefore, we conclude that neither the expression nor the activity of the I $\mathrm{B}$ or NF- $\mathrm{kB}$ proteins has been altered significantly in the Bcl-3(-/-) mice.

\section{Normal mature B- and T-cell subsets}

The development of apparently normal, healthy Bcl-3(-|-| mice suggested that lymphocyte populations would be normal. To confirm this, we performed a flow cytometric analysis of splenocyte populations (Fig. 3). No difference was observed in the expression of CD4, CD8, B220, $\operatorname{IgM}, \operatorname{Ig} \kappa$, and $\operatorname{Ig} \lambda$. We also tested other surface markers including TCR $\alpha \beta, \mathrm{TCR} \gamma \delta$, IL-2R $\alpha, \mathrm{HSA}, \mathrm{CD} 43, \mathrm{BP} 1$, Macl, and Grl (data not shown). The differences in the cell surface expression of these different receptors were indistinguishable between normal and $\mathrm{Bcl}-3(-\mid-)$ mice. We also looked at the ability of these cells to proliferate in response to various mitogenic agents including IL-2, IL-4, IL-5, IL-6, LPS, and combinations of anti-IgM, concavalin A, anti-CD3, anti-CD28, PMA, and ionomycin. We failed to detect any difference between the wild-type and Bcl-3(-/-) mice (data not shown). Additionally, IL-2 production levels are normal in Bcl-3(-/ -$)$ mice, in response to the stimuli mentioned above (data not shown).

A

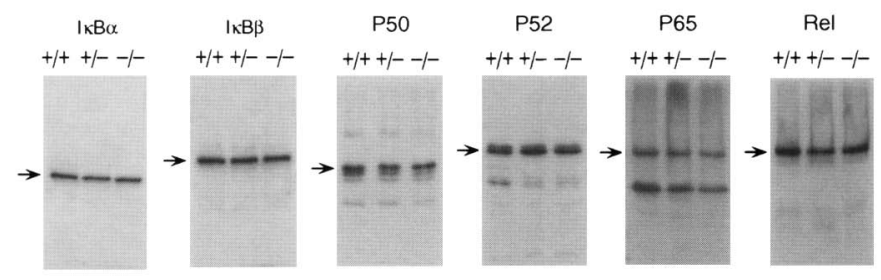

B

$\frac{\text { B-cells }}{+1+-1-+1+-1-}$
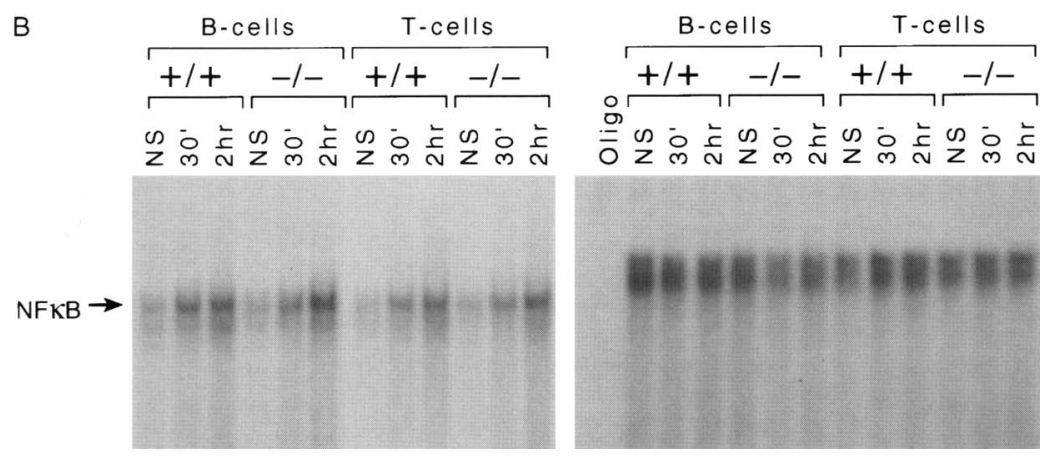

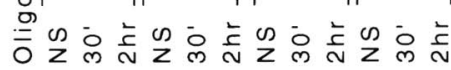

C

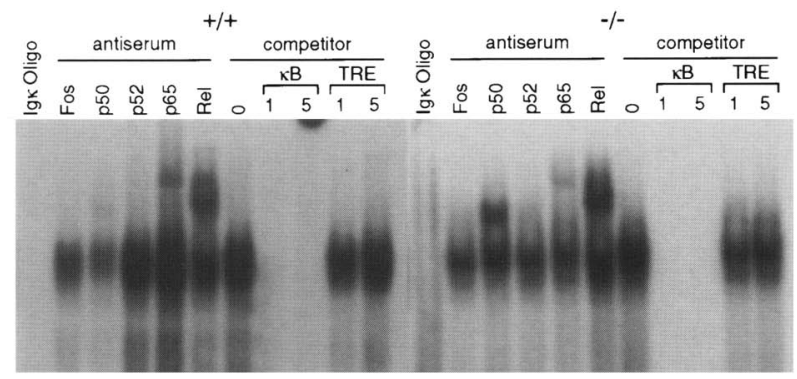

Figure 2. Normal expression of all $\mathrm{I}_{\kappa} \mathrm{B}$ and NF- $\mathrm{kB}$ proteins, induction of NF- $\mathrm{B}$ and composition of NF-kB/Rel DNA-binding complexes. (A) Western blot analysis of protein extracts prepared from purified splenocytes. Each protein blot was incubated with serum specific to IкB $\alpha, I_{\kappa} B \beta, p 50$, p52, p65 and c-Rel. Arrows indicate location of specific protein bands blockable by addition of antigen. $(B)$ EMSA of $5 \mu \mathrm{g}$ of nuclear extracts from nonstimulated (NS), or PMAand ionomycin-stimulated $\mathrm{B}$ and $\mathrm{T}$ cells. An Igк кB oligo probe and an Oct1 oligo probe containing the appropriate DNAbinding sites were used. (C) Composition of NF- $\kappa$ B/Rel complexes induced by LPS treatment in wild-type and $b c l-3(-/-)$ splenocytes assessed by EMSA with antibody inhibition. Purified specific antibodies (5 $\mu g$ ) to each NF- $\mathrm{B} / \mathrm{Rel}$ protein were preincubated with nuclear extracts prior to addition of the Ig $\kappa \kappa B$ oligonucleotide probe. A c-Fos-specific antibody was used as a control serum. Specific complexes were inhibited by competition with 1 and 5 ng of unlabeled oligonucleotide containing an $\operatorname{Ig}_{\kappa}$ $\kappa \mathrm{B}$ site but not the TRE control. 


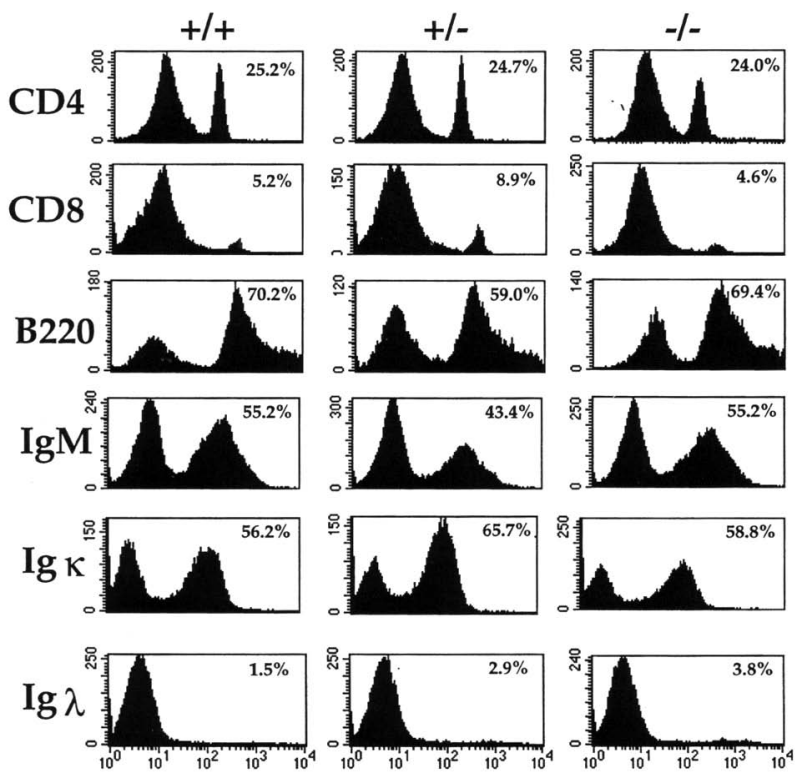

Figure 3. Normal expression of surface markers on mature Band T-cell subsets. Relatively equal numbers of lymphocytes were obtained from single-cell suspensions prepared from spleens of Bcl-3(-/-) and control littermates (data not shown). Splenocytes were stained with labeled antibodies and analyzed by flow cytometry as described in Materials and Methods. The percentages of positive cells for indicated surface markers are shown.

Basal and specific antibody production in Bcl-3(-/-) mice

Because Bcl-3 is expressed most abundantly in lymphocytes, we questioned whether the $\mathrm{Bcl}-3(-/-)$ mice function normally with regard to antibody production. We measured basal production of resting serum immunoglobulin in $\mathrm{Bcl}-3(-/-)$ and control littermates by enzyme linked immunosorbant assays (ELISA). Total serum immunoglobulin levels were approximately equal (Fig. 4A). To test specific antibody production, we vaccinated these animals with $100 \mu \mathrm{g}$ of heat-killed, whole-cell extracts made from overnight cultures of $S$. pneumoniae. Thirty days after vaccination, the animals were bled and their immunoglobulin levels were determined by ELISA (Fig. 4B). Surprisingly, the level of total IgM, IgG1, IgG2b, and IgG3 heavy chains, as well as the $\kappa$ and $\lambda$ light chains were elevated slightly in the $\mathrm{Bcl}-3(-/-)$ serum compared with the controls. However, the Bcl-3(-/-) serum lacked specific antibodies against the $S$. pneumoniae antigens (Fig. 4C). Therefore, although Bcl-3(-1-) mice are able to generate greater than normal levels of antibodies in response to vaccination, they are unable to generate specific antibodies.

In vivo growth rates and resistance to pathogenic challenges

In addition to specific antibody or acquired immune re-

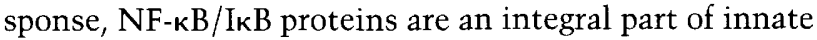
immunity. Therefore, we examined the innate immune response of $\mathrm{Bcl}-3(-/-\mid$ mice. The ability of the $\mathrm{Bcl}-3|-|-\mid$
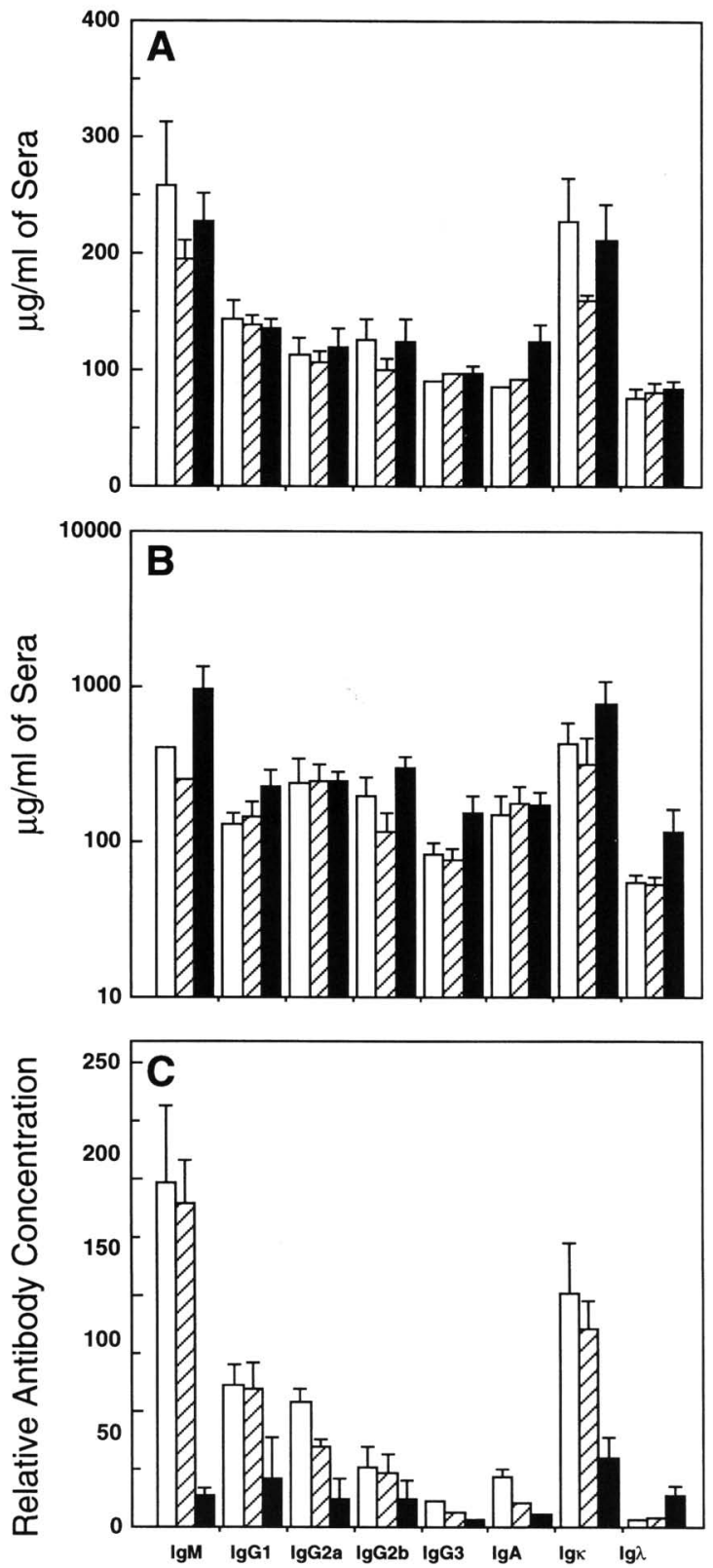

Figure 4. Resting and specific antibody production. (A) Preimmunization titers: Serum concentrations of immunoglobulin isotypes from unimmunized wild-type (open bars; $+/+\mid$ heterozygous (hatched bars; $+/-$ ) and Bcl-3 knockout (solid bars; $-/-$ ) mice. Serum immunoglobulins were standardized against a $c$ Fos monoclonal antibody. (B) Postimmunization titers: Serum concentrations of immunoglobulin isotypes from mice 30 days after vaccination with $100 \mu \mathrm{g}$ of whole-cell, $S$. pneumoniae extract. $(C)$ Specific antibody titers: Relative antibody titers of immunoglobulin isotypes specific for $S$. pheumoniae antigens 30 days after vaccination. Values represent the O.D. of immunized serum after standardization with the preimmune serum. Each bar represents the average value obtained from three mice by ELISA. 
mouse to respond to and control infections with the major classes of pathogens was tested using protocols described by Sha et al. (1995) for the p50(-/-) mice. In this way we could compare our results with those of the p50(-/-) mice. As well, we mated the Bcl-3(-/-) mice with the $\mathrm{p} 50(-/-)$ mice in an effort to understand the in vivo relationship between Bcl-3 and p50. We challenged the mice with the extracellular Gram-negative bacteria Escherichia coli or Gram-positive S. pneumoniae, or the intracellular bacteria L. monocytogenes, and the murine encephalomyocarditis (EMC) virus.

The Bcl-3(-/-) mice challenged with $2 \times 10^{7} \mathrm{E}$. coli were able to control and survive the infection similar to the control mice (Fig. 5A,B). Listeria-infected Bcl-3(-/-) mice were able to cope with the infection and survive as well as the wild-type mice (Fig. 5D), but the Listeria displayed a growth advantage in the $\mathrm{Bcl}-3(-/-)$ mice. Five days after an intraperitoneal injection with $10^{4}$ bacteria, the wild-type mice had $>500$ bacteria in their spleens whereas several of the Bcl-3(-/-) mice had $\sim 2$ logs more (Fig. 5C). The introduction of the p50 mutation into these animals greatly enhanced this phenotype. The double heterozygous animals had a similar bacteria load as the Bcl-3/-/-) mice. The double knockout mice had $\sim 10^{5}$ times as much as the wild type, and in one case the infection was lethal.

Control and elimination of the aggressive, extracellular, gram-positive pathogen $S$. pneumoniae requires a potent humoral immune response (Mims 1990). Correspondingly, the Bcl-3(-/-) mouse is incapable of mounting this kind of response (Fig. 4), and is highly susceptible to $S$. pneumoniae infections. One day after an intraperitoneal injection with only 10 bacteria, the Bcl-3|-/ - | mice had almost $10^{10} \mathrm{cfu}$ of $S$. pneumoniae per milliliter of blood (Fig. 5E). The sepsis in these mice can be seen clearly in blood smears from these animals (Fig. 6). The heterozygous littermates did better, whereas the wild-type mice had a stochastic response (Fig. 5E). In $>30$ mice injected with various doses of $S$. pneumoniae, including one cfu in an experiment, we never observed a Bcl-3(-1-) mouse surviving longer than 2 days. In these experiments the heterozygous mice exhibited a genedose effect, surviving $\sim 30 \%$ of the challenges, whereas the wild-type mice survived $-60 \%$ of the time (Fig. $5 \mathrm{~F}$ ). As a control for these experiments we included challenges with noncapsulated $S$. pneumoniae, which was not pathogenic (Fig. 5F). Once again, the addition of the p50 mutation exacerbates disease. Whereas all p50(+/-) mice (Sha et al. 1995) and Bcl-3/+/-) (this study) challenged survived more than $24 \mathrm{hr}$ post-infection, only $40 \%$ of the double heterozygous mice survived that long (Fig. 5F). We were also interested to know if the phenotype of these mice could faithfully reflect that of mice without antibodies. Therefore, we used the $\operatorname{Ig} M(-/-)$ mouse (Kitamura et al. 1991) as a control (Figs. 5E,F). The results of these experiments indicate that the defective humoral response in the $\mathrm{Bcl}-3|-|-\mid$ mouse is likely to be the cause of the demise of these animals following infection with $S$. pneumoniae. Furthermore, the data suggest that p50 and Bcl-3 may interact to activate genes in the immune system because heterozygous double knockouts have a more severe consequence.

\section{Loss of splenic germinal centers in $\mathrm{Bcl}-3(-/-)$ mice}

In lieu of our antibody and infection data, do the Bcl-3(-/-) mice form germinal centers? To answer this question we examined histologic sections of spleens from wild-type and Bcl-3(-/-) mice (Fig. 7). Because p50(-/-) mice also exhibit similar susceptibilities to infectious agents (Fig. 5), we included them in the germinal center assays. Sections were stained with either Nuclear Fast Red, fluorescein isothiocyanate (FITC) conjugated peanut agglutinin, or immunolabeled phycoerythrin (PE) conjugated-antiB220 antibody and FITC conjugated anti-CD3, followed by visual light or confocal microscopy. Both the wild-type and p50(-/-) mice display a normal distribution of well-formed germinal centers, whereas the white pulp in the $\mathrm{Bcl}-3(-/-)$ mice are void of germinal centers as determined by PNA staining. A close inspection of the white pulp in the $\mathrm{Bcl}-3(-/-)$ mice revealed that the $\mathrm{B}$ cells and $T$ cells are disorganized, compared with the normal distribution observed in the wild-type and p50(-/-) spleens. This phenotype, previously reported for cytokine (Crowe et al. 1994), cytokine receptor (Neumann et al. 1996), costimulatory receptor (Kawabe et al. 1994), costimulatory ligand (Xu et al. 1994), and transcription factor (Kim et al. 1996; Schubart et al. 1996) knockout mice models, is a complex one. The cause of the loss of germinal centers is presently not well understood.

\section{Discussion}

We have generated mice devoid of $b c l-3$, a member of the IкB family, by targeted disruption of the gene. The resulting animals are apparently normal, in that they exhibit no alterations in their overall anatomy or their behavior. Despite the predictions made about the role of $b c 1-3$ in cell regulation based on the facts that $(1)$ it was cloned as the translocation breakpoint gene in patients with B-cell chronic lymphocytic leukemia; and (2) the uninterrupted transcription of the gene results in $b c l-3$ mRNA levels that are at least 3.5 times higher than nor$\mathrm{mal}$ in these patients, and $b c l-3$ is structurally related to proteins known to regulate the cell cycle /Ohno et al. 1990); we find no evidence for this in our mouse model. Also, we have not gained any insight as to how Bcl-3 functions as a transforming protein. Additionally, we have examined the immune cells in these animals and have found no difference between the mutant mice and the wild-type. The development of phenotypically normal animals, however, has allowed us to define the role of Bcl-3 in immune responses. The data presented here argue that $\mathrm{Bcl}-3$ is essential for the production of antigen-specific antibodies, germinal center formation, and immune responses to pathogens. A potential concern in the interpretation of the results of gene targeting experiments involving a single member of a family of related 

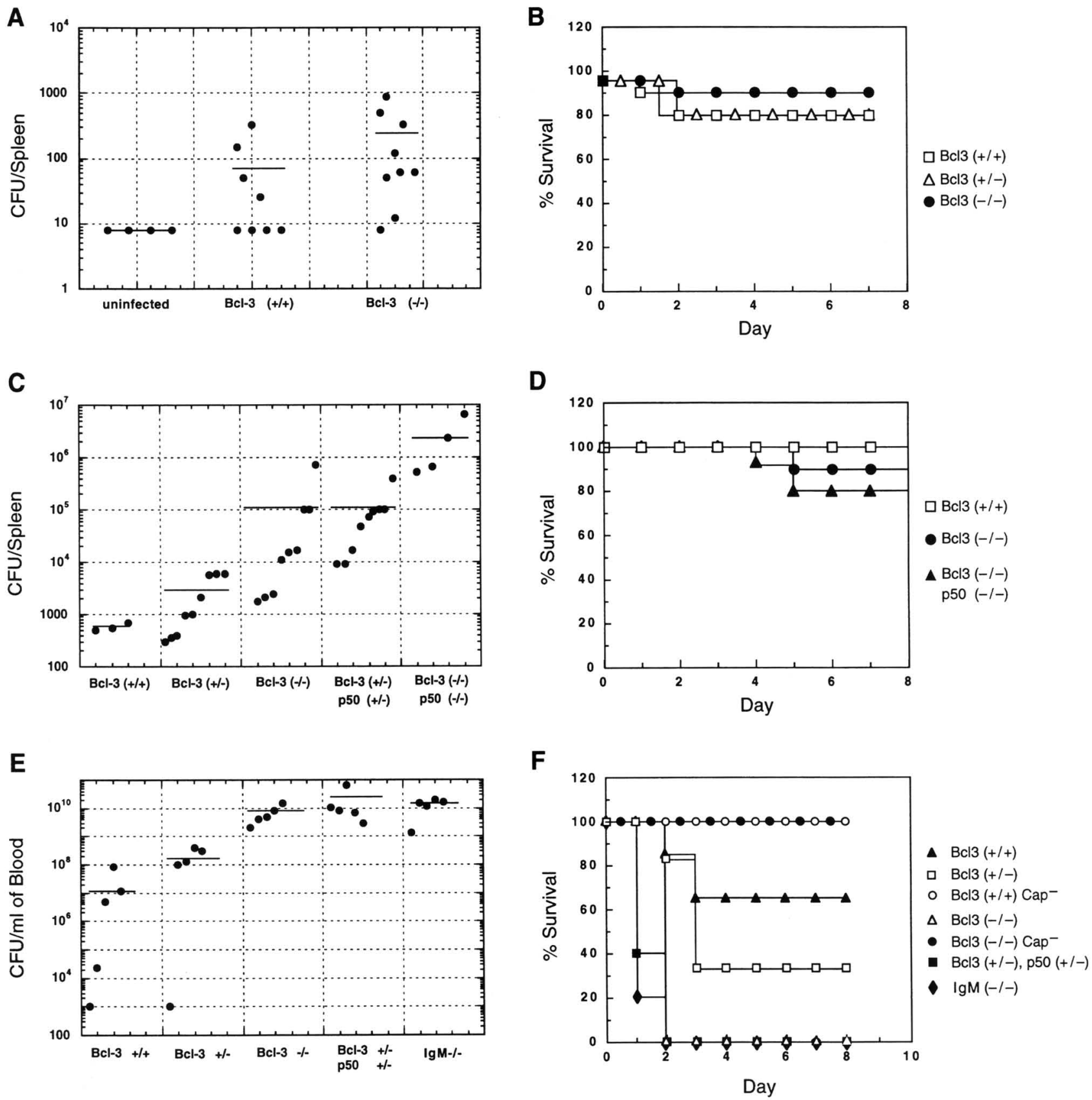

Figure 5. In vivo growth rates and survival of mice challenged with pathogens. Clearance of $(A)$ E. coli, $(C)$ L. monocytogenes, and (E) S. pneumoniae in wild-type, heterozygous, and Bcl-3 knockout mice injected intraperitoneally with $2 \times 10^{7}, 10^{4}$, and 10 bacteria colony-forming unit (cfu) for 8, 6, and 1 day, respectively. Also included in $E$ are experiments with the Bcl-3/p50 double heterozygous and the IgM knockout mouse. Each circle represents the bacterial cfu from the spleen homogenate $(A, C)$ or from the blood $(E)$ of a single animal. The percentage of surviving wild-type $(\square)$, heterozygous $(\Delta)$ and Blc-3 knockout $(\bullet)$ mice, as well as Bcl-3/p50 double heterozygous $(\square)$ and the IgM knockout $(O)$ was monitored over a time. As a control in $F$, the nonencapsulated $S$. pneumoniae $(O$ and $\Delta)$ were also injected. Each experiment was done with five or more mice. Survival of mice challenged with $E$. coli $(B), L$. Monocytogenes $(D)$, and $S$. pneumoniae $\{E\rangle$. Each symbol represents an individual mouse for cfu experiments. Survival experiments represent the results of 7 or more mice.

proteins is that redundancy and compensation by other family members can mask the actual importance of a particular family member. As was the case of the previ-

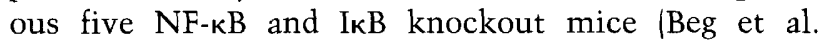

1995a,b; Kontgen et al. 1995; Sha et al. 1995; Welh et al. 1995), no compensation or redundancy could be detected in that a clear phenotype persists in the Bcl-3(-/-) mouse (Figs. 2,3). 

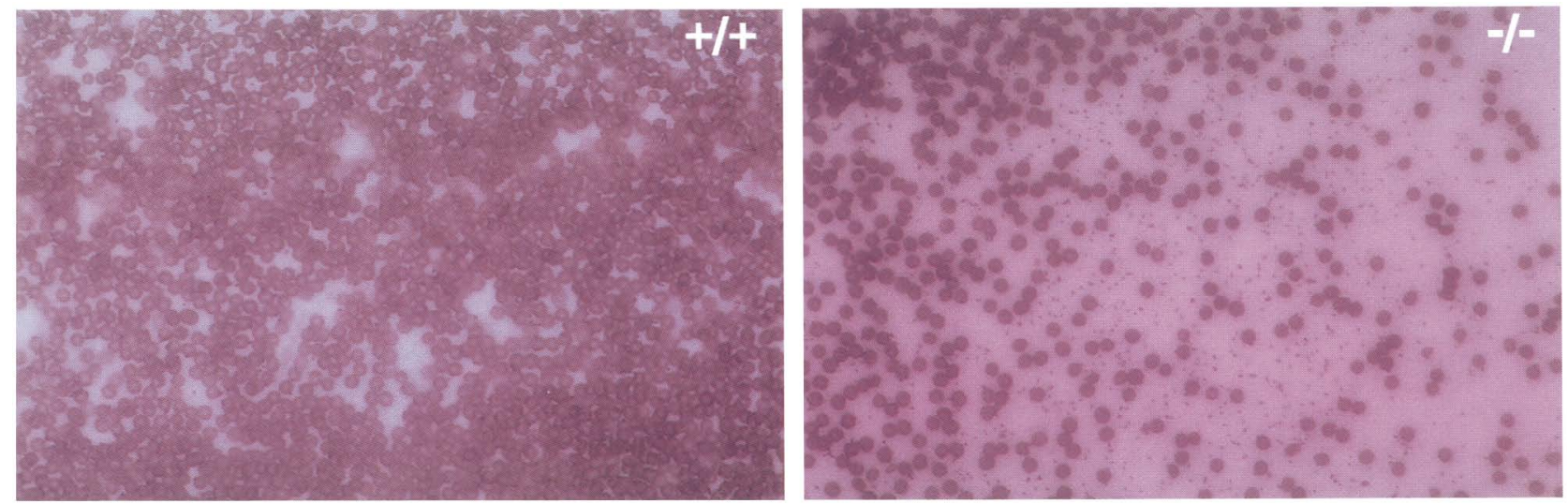

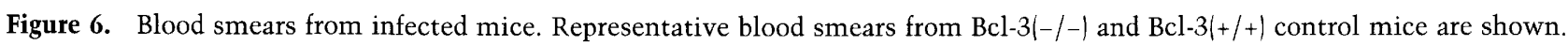

The role of Bcl-3 in lymphocytes

The data presented here demonstrate that Bcl-3 is essential for the efficient production of antigen-specific antibodies (Fig. 4). Although Bcl-3(-/-) mice have normal resting immunoglobulin levels and are capable of producing antibodies in response to an antigenic challenge, they fail to produce antibodies that specifically recognize the antigen. The precise mechanism of this disorder remains elusive. However, the observation that the Bcl$3(-/-)$ mice do not have germinal centers (Fig. 7), provides one explanation. We interpret the ELISA data in the following way. The Bcl-3(-/-) mice have a normal number of $B$ and $T$ cells, which are capable of maintaining normal levels of immunoglobulins in the naive animals. Following immunization with $S$. pneumoniae, a

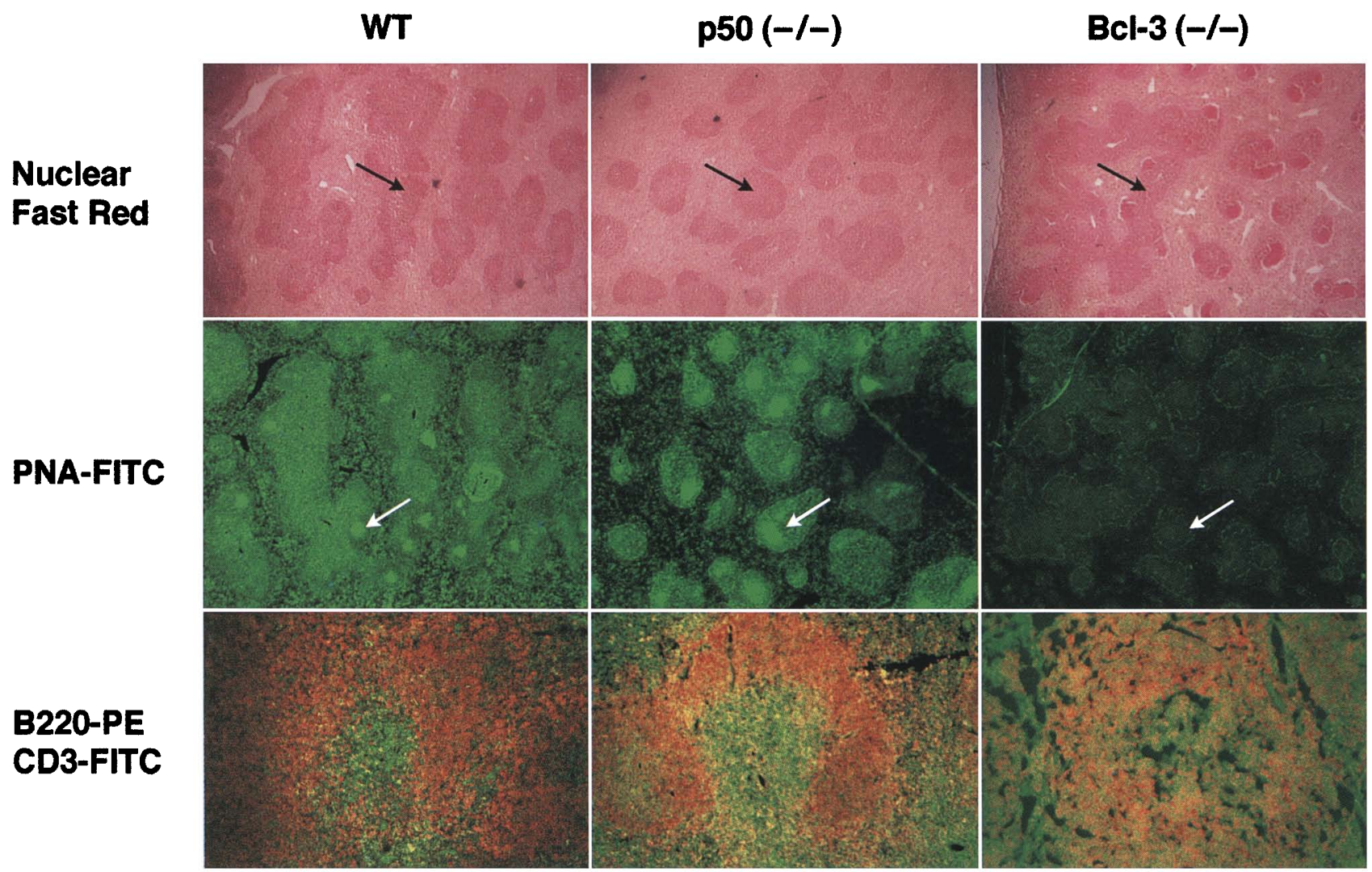

Figure 7. Germinal center formation. Histology sections taken from spleens of wild-type, p50(-/-), and Bcl-3(-/-) mice. Sections were stained with either Nuclear Fast Red or FITC-conjugated PNA or immunolabled with PE-conjugated anti-B220 and FITC-conjugated anti-CD3 antibodies. The black arrows indicate the white pulp. The white arrows indicate the presence or absence of germinal centers. 
huge population of $B$ cells become stimulated nonspecifically by LPS. Because there are no germinal centers, clonal expansion and somatic mutation of B cells expressing antigen receptors that specifically recognize $S$. pneumoniae antigens, cannot occur (Rajewsky 1996). The result is the production of random antibodies. An additional explanation is that the $\mathrm{Bcl}-3(-/-)$ mice have defects in lymphokine production and in antigen processing and presentation.

\section{The requirement of $B c l-3$ to resist infection}

The results from in vivo challenge experiments with three different pathogens, E. coli, L. monocytogenes, and $S$. pneumoniae, reflect the importance of Bcl-3 in regulating responses to infection. In the first case, Bcl- 3 is completely dispensable with respect to survival from an extracellular gram-negative bacterial infection. Although antibodies are very useful (Mims 1990), here we see that in their absence polymorphonuclear phagocytes are likely to be sufficient to fight off $E$. coli.

The intracellular bacterium $L$. monocytogenes survives in nonactivated macrophages (Mims 1990). Clearance of this microbe has been shown to depend on the ability of the host to activate macrophages by cytokines produced by $\mathrm{T}$ and NK cells, most notably interferon- $\gamma$ (Bancroft et al. 1991). Although our data here shows that a specific humoral response is not required for survival, the elevated number of bacteria observed in the spleens of the Bcl-3(-/ -1 mice following infection could be the result of Listeria entering macrophages through receptors, other than Fc receptors, which do not trigger a respiratory burst and bactericidal activity of these cells.

The critical nature of a protective humoral response against an aggressive Gram-positive bacterial challenge from $S$. pneumoniae has been well documented (Mims 1990). The Bcl-3(-/-) mouse is no exception to this rule. In our hands, the infection of these animals with any dose of S. pneumoniae is always fatal within a $48 \mathrm{hr}$ time frame. To provide additional evidence that the lack of protective antibodies is the cause of the huge bacterial load observed in these animals $24 \mathrm{hr}$ after infection, we showed that challenging mice with no antibodies, the $\operatorname{IgM}(-\mid-)$ mice, generates the same result (Fig. 5E). Therefore, from this data we extrapolate that $\mathrm{Bcl}-3$ is required for a protective humoral immune response in vivo.

\section{Similarities and differences between the Bcl-3 and p50 knockout mice}

Virtually all molecular models for Bcl-3 focus around its interaction with NF- $\mathrm{kB}$. Therefore, a central issue to the relationship between $\mathrm{Bcl}-3$ and $\mathrm{p} 50$ is whether $\mathrm{Bcl}-3$ acts antagonistically or synergistically with p50 in NF-кBmediated transcription. In a series of experiments, we tested whether the $\mathrm{Bcl}-3(-\mid-)$ mouse would become more susceptible to infection with bacteria when the p50 null mutation was introduced into these animals. We observed an enhanced phenotype in the double heterozygous and homozygous mice (Fig. 5E,F). Correspond- ingly, the Bcl-3/- $/-\mid$ mice and the p50(-/ -$)$ mice have a remarkably similar response to pathogenic challenges.

However, there are several striking differences between the Bcl-3(-/-) and the p50 $(-/-)$ mice. Whereas both the Bcl-3(-/-) and the p50(-/-) mice exhibit defects in specific antibody production, they are likely from different causes. As we have mentioned above, the Bcl-3(-/-) mice are unable to form germinal centers whereas the p50(-/-) mice appear to be normal in this regard. The inability of the p50(-/ -1 mice to produce specific antibodies is likely attributable to the defect in B-cell proliferation (Sha et al. 1995), which was not seen in the Bcl$3|-|-\mid$ mice. There are two additional differences: unresponsiveness to LPS and resistance to EMC virus infection. These phenotypes reported previously for the p50(-/-) mice (Sha et al. 1995), were not observed in the Bcl-3(-/-) mice (data not shown).

Our studies have established a role for Bcl-3 in immune function, but do not distinguish decisively between the role of $\mathrm{Bcl}-3$ as an agonist or antagonist of NF- $\mathrm{kB}$ activity. Although the similar phenotypes of the Bcl-3 and p50 knockout mice argue against the antagonism models, synergy can only be inferred. Since there are several differences, the similar phenotype could be caused by independent mechanisms. As well, the enhanced phenotype in the double knockout mice could be caused by the combination of different defects. However, these differences clearly establish that Bcl-3 is capable of acting independently of p50 in vivo. One possibility is that $\mathrm{Bcl}-3 / \mathrm{p} 52$ complexes are essential. The crossing of Bcl-3(-/-) mice with mice where other members of the NF-кB family have been deleted (i.e., p52), will be very informative to assess the role of $\mathrm{Bcl}-3(-|-|)$ in the mouse immune system.

\section{Materials and methods}

Construction of targeting vector

Phage clones representing the $b c l-3$ locus were isolated from a 129 /SV genomic library (Stratagene) using a $b c l-3$ cDNA probe. The SalI inserts of the phage clones were introduced into pGEM11Zf (Promega) and characterized further. A 2.5-kb BgIII/ SacIl fragment (SacII site in the first exon) was ligated to the $3^{\prime}$ site and an 8.5-kb NotI (in exon 6)/SalI (derived from the $\lambda$ phage) fragment was ligated to the 5 ' of the PGKHyg expression cassette (Adra et al. 1987), respectively. The PGKHyg cassette is therefore orientated in opposite transcriptional direction. The targeting fragment was excised from the vector using a SalI digest. Probe A is a 600-bp BglII fragment at the 5' site external from the targeting fragment. Probe $B$ is derived from the hygromycin resistance gene.

\section{ES cell culturing and generation of bcl-3 mutant mice}

Targeting fragment $(75 \mu \mathrm{g})$ was electroporated into $150 \times 10^{6}$ E14 ES cells (Hooper et al. 1987) and hygromycin-resistant colonies were selected and cultured as described (te Riele et al. 1992). EcoRI-digested DNA isolated from 180 colonies were screened by Southern blotting using probes A and B. Targeted ES cell clones were used for injection into B6 blastocysts as described (Robanus Maandag et al. 1994). Chimeric male offspring 
were crossed to FVB/ $\mathrm{N}$ mice and $b c l-3|+|-\mid$ offspring were identified by Southern blotting. $b c l-3(-1-)$ mice were derived subsequently from $b c l-3|+|-\mid$ intercrosses.

\section{Western blots}

Approximately $10 \mu \mathrm{g}$ of protein extracts from splenocytes of Bcl-3(- $-\mid-)$ and controls were loaded onto individual lanes of a $10 \%$ SDS-PAGE gel for NF- $\mathrm{kB}$ proteins or $12 \%$ SDS-PAGE gel for I $\mathrm{K}$ proteins, electrophoresed in one dimension and transferred to immobilon P membranes as described (Barroga et al. 1995). The membranes were then blocked with $2 \%$ nonfat milkTBST (10 mm Tris-HCl (pH 8.0), $150 \mathrm{~mm} \mathrm{NaCl}, 0.05 \%$ Tween 20) for $1 \mathrm{hr}$ and incubated with specific antibody at a dilution of $1: 1000$ in $2 \%$ nonfat milk-TBST for $2 \mathrm{hr}$ at room temperature. After three washes with TBST, filters were incubated with either ${ }^{125}$ I-labeled protein A (New England Nuclear) for Bcl-3, or with the secondary antibody (goat anti-rabbit IgG-horseradish peroxidase conjugated) for $1 \mathrm{hr}$. Antibody-reactive bands were revealed by chemiluminescent detection (ECL Western detection kit; Amersham International) or in the case of bcl-3, phosphoimagery analysis was performed as described in (Schwarz et al. 1996).

\section{EMSA assays}

Preparation of nuclear and cytoplasmic extracts, EMSA, and antibody inhibition assays to identify components of NF- $\mathrm{kB} /$ Rel complexes were performed as described previously (Schwarz et al. 1993; Chiao et al. 1994; Miyamoto et al. 1994a,b,c). A DNA probe was generated by annealing two oligonucleotides containing the $\mathrm{MHCl}$, Igк $\kappa \mathrm{B}$, Oct I, or AP-1 DNA-binding sites and end-labeling them with $\left[\gamma_{-}{ }^{32} \mathrm{P}\right] \mathrm{ATP}$ by polynucleotide kinase (New England Biolabs).

\section{Flow cytometry}

A FACScan flow cytometer and the Cell Quest plotting program were used (Becton-Dickinson). PE-conjugated antibodies against mouse CD4, CD8, and IgM (Pharmingen) or a biotinylated antiCD45R/B220 and Ig $\lambda$ (Pharmingen) labeled with streptavidinFITC (Molecular Probes), were used to stain the primary splenocytes.

\section{Generation of single cells and cultures of primary splenocytes}

Whole spleens were removed from mice and squashed between two glass slides. The squash was resuspended and washed once with PBS, the red blood cells were lysed in $\mathrm{NH}_{4} \mathrm{Cl}_{2}$ and the live white blood cells were isolated by centrifugation on a layer of Ficol-Hypaque (Pharmacia). The buffy coat was washed once in PBS and the cells were maintained in RPMI 1640 medium containing $10 \%$ defined fetal calf serum (Hyclone), penicillin-streptomycin, and $50 \mathrm{~mm} \beta$-mercaptoethanol. Cells were stimulated in vitro with PMA and ionomycin (Sigma) or LPS (Sigma) as described previously (Miyamoto et al. 1994a,b,c). >98\% pure populations of splenic B cells and T cells were obtained by FACS using PE-conjugated anti-B220 and FITC-conjugated anti-CD3 (Pharmingen).

\section{Immunoglobulin isotype analysis}

Sera were prepared from 6-week-old Bcl-3(-/-) and control, sexmatched littermates. Following the preimmune bleeds, these mice were immunized with $100 \mu \mathrm{g}$ of heat-killed, S. pneumoniae whole-cell extracts in PBS. This vaccine was injected intramuscularly in the hind legs of these animals. Thirty days following immunization sera were prepared from these mice. Immunoglobulin isotypes were quantitatively determined using the Mouse Typer Sub-Isotyping Kit (Bio-Rad). An anti-c-Fos monoclonal antibody was used as the standard. The ELISA plates were read in a MR 700 Microplate Reader (Dynatech Laboratories). The relative titers against $S$. pneumoniae antigens were determined by coating the ELISA plate with $100 \mu \mathrm{g} /$ well of the vaccine for $1 \mathrm{hr}$, blocking with $100 \mu \mathrm{g} /$ well BSA followed by antibody absorption and isotyping according to the manufacturer's instructions.

\section{Histology and immunocytochemistry}

Tissues from mice were used in morphology and immunolabeling studies as we have described previously (Dai et al. 1995). Sections were stained with either Nuclear Fast Red (Sigma) or labeled with FITC-conjugated PNA (Vector) or immunolabeled with PE-conjugated anti-B220 and FITC-conjugated anti-CD3 antibodies (Pharmingen). Bright-field sections were imaged and photographed on a Vanox AH2 microscope (Olympus) using Ektachrome $100 \mathrm{HC}$ film (Kodak). Selected frames were digitized using Leaf Lumina digital camera (Leaf Systems). Fluorescent sections were imaged using a Bio-Rad MRC600 confocal microscope equipped with a krypton/argon laser and coupled to an Axiovert $135 \mathrm{M}$ microscope (Zeiss). Images were collected using the $\mathrm{K} 1 / \mathrm{K} 2$ block combination; each wavelength was collected using a separate and specific excitation filter and imaged on separate photomultiplier tubes using the COMOS operating system (Bio-Rad). Bright-field and fluorescent digital images were processed using a power Macintosh 8100 (Apple Computer) running Photoshop 3.01 (Adobe Systems) and Collage 2.01 (Specular International). Composited images were output on a Fuijx Pictography 3000 digital photographic printer (Fuji Photo Film)

\section{Pathogenic challenges}

L. monocytogenes (43251) were obtained from the ATCC. A clinical isolate of $E$. coli (SDSI1) was obtained from the University of California San Diego Medical Center. S. pneumoniae were obtained from the Laboratory of Molecular Infectious Diseases at The Rockefeller University. The growth of the pathogens and the infection protocols were performed as described by Sha et al. (1995).

\section{Acknowledgments}

We are grateful to Drs. Larry Kerr and Paul Chiao who initiated this work and generated the $\lambda$ phages containing the $b c l-3$ genomic sequences. We thank W.C. Sha and D. Baltimore for providing us with p50(-/ -1 mice and helpful advice for these studies. F. Gage, D. Peterson and L. Kitabayashi helped us prepare the histology and immunocytochemistry. We thank E.I. Tuomanen for providing us with the $S$. pneumoniae and S. Huber and $\mathrm{K}$. Knowlton for providing us with the EMC virus. We thank members of the Verma Lab for their constant support. This work was supported by funds from the National Institutes of Health, the American Cancer Society, and the H.N. and Frances C. Berger Foundation. E.M.S. is supported by a fellowship from the Arthritis Foundation and the National Multiple Sclerosis Society. I.M.V. is an American Cancer Society professor of molecular biology.

The publication costs of this article were defrayed in part by payment of page charges. This article must therefore be hereby 
marked "advertisement" in accordance with 18 USC section 1734 solely to indicate this fact.

\section{References}

Adra, C.N., P.H. Boer, and M.W. McBurney. 1987. Cloning and expression of the mouse pgk-1 gene and the nucleotide sequence of its promoter. Gene 60: 65-74.

Bancroft, G.J., R.D. Schreiber, and E.R. Unanue. 1991. Natural immunity: A T-cell independent pathway of macrophage activation, defined in the scid mouse. Immunol. Rev. 124: 524.

Barroga, C.F., J.K. Stevenson, E.M. Schwarz, and I.M. Verma. 1995. Constitutive phosphorylation of I kappa B alpha by casein kinase II. Proc. Natl. Acad. Sci. 92: 7637-7641.

Beg, A.A., W.C. Sha, R.T. Bronson, and D. Baltimore. 1995a. Constitutive NF-kappa B activation, enhanced granulopoiesis, and neonatal lethality in $\mathrm{I}_{\kappa} \mathrm{B} \alpha$-deficient mice. Genes \& Dev. 9: 2736-2746.

Beg, A.A., W.C. Sha, R.T. Bronson, S. Ghosh, and D. Baltimore. 1995b. Embryonic lethality and liver degeneration in mice lacking the RelA component of NF-kappa B. Nature 376: $167-170$.

Bours, V., G. Franzoso, V. Azarenko, S. Park, T. Kanno, K. Brown, and U. Siebenlist. 1993. The oncoprotein Bcl-3 directly transactivates through kappa $B$ motifs via association with DNA-binding p50B homodimers. Cell 72: 729-739.

Caamano, J.H., P. Perez, S.A. Lira, and R. Bravo. 1996. Constitutive expression of $\mathrm{Bcl}-3$ in thymocytes increases the DNA binding of NF-kB1 (p50) homodimers in vivo. Mol. Cel. Biol. 16: $1342-1348$.

Chiao, P.J., S. Miyamoto, and I.M. Verma. 1994. Autoregulation of I kappa B alpha activity. Proc. Nat1. Acad. Sci. 91: 28-32.

Crowe, P.D., T.L. VanArsdale, B.N. Walter, C.F. Ware, C. Hession, B. Ehrenfels, J.L. Browning, W.S. Din, R.G. Goodwin, and C.A. Smith. 1994. A lymphotoxin-beta-specific receptor [see Comments]. Science 264: 707-710.

Dai, Y., E.M. Schwarz, D. Gu, W.W. Zhang, N. Sarvetnick, and I.M. Verma. 1995. Cellular and humoral immune responses to adenoviral vectors containing factor IX gene: Tolerization of factor IX and vector antigens allows for long-term expression. Proc. Nat1. Acad. Sci. 92: 1401-1405.

Franzoso, G., V. Bours, S. Park, M. Tomita-Yamaguchi, K. Kelly, and U. Siebenlist. 1992. The candidate oncoprotein Bcl-3 is an antagonist of p50/NF-kappa B-mediated inhibition. $\mathrm{Na}$ ture 359: 339-342.

Franzoso, G., V. Bours, V. Azarenko, S. Park, M. TomitaYamaguchi, T. Kanno, K. Brown, and U. Siebenlist. 1993. The oncoprotein Bcl-3 can facilitate NF-kappa B-mediated transactivation by removing inhibiting p50 homodimers from select kappa B sites. EMBO I. 12: 3893-3901.

Fujita, T., G.P. Nolan, H.C. Liou, M.L. Scott, and D. Baltimore. 1993. The candidate proto-oncogene bcl-3 encodes a transcriptional coactivator that activates through NF-k B p50 homodimers. Genes \& Dev. 7: 1354-1363.

Hatada, E.N., A. Nieters, F.G. Wulczyn, M. Naumann, R. Meyer, G. Nucifora, T.W. McKeithan, and C. Scheidereit. 1992. The ankyrin repeat domains of the NF-kappa B precursor pl05 and the protooncogene bcl-3 act as specific inhibitors of NF-kappa B DNA binding. Proc. Natl. Acad. Sci. 89: $2489-2493$.

Hooper, M., K. Hardy, A. Handyside, S. Hunter, and M. Monk. 1987. HPRT-deficient (Lesch-Nyhan) mouse embryos derived from germline colonization by cultured cells. Nature 326: $292-295$.
Inoue, J., T. Takahara, T. Akizawa, and O. Hino. 1993. Bcl-3, a member of the I kappa B proteins, has distinct specificity towards the Rel family of proteins. Oncogene 8: 2067-2073.

Kawabe, T., T. Naka, K. Yoshida, T. Tanaka, H. Fujiwara, S. Suematsu, N. Yoshida, T. Kishimoto, and H. Kikutani. 1994. The immune responses in CD40-deficient mice: Impaired immunoglobulin class switching and germinal center formation. Immunity 1: 167-178.

Kerr, L.D., C.S. Duckett, P. Wamsley, Q. Zhang, P. Chiao, G. Nabel, T.W. McKeithan, P.A. Baeuerle, and I.M. Verma. 1992. The proto-oncogene bcl-3 encodes an IK B protein. Genes \& Dev. 6: 2352-2363.

Kim, U., X.F. Qin, S. Gong, S. Stevens, Y. Luo, M. Nussenzweig, and R.G. Roeder. 1996. The B-cell-specific transcription coactivator OCA-B/OBF-1/Bob-1 is essential for normal production of immunoglobulin isotypes. Nature 383: 542-547.

Kitamura, D., J. Roes, R. Kuhn, and K. Rajewsky. 1991. A B cell-deficient mouse by targeted disruption of the membrane exon of the immunoglobulin $\mu$ chain gene. Nature 350: 423426.

Kontgen, F., R.J. Grumont, A. Strasser, D. Metcalf, R, Li, D. Tarlinton, and S. Gerondakis. 1995. Mice lacking the c-rel proto-oncogene exhibit defects in lymphocyte proliferation, humoral immunity, and interleukin-2 expression. Genes \& Dev. 9: 1965-1977.

Lenardo, M. and U. Siebenlist. 1994. Bcl-3-mediated nuclear regulation of the NF-kappa B trans-activating factor. Immunol. Today 15: 145-147.

Mims, C.A. 1990. The pathogenesis of infectious disease, Academic Press, San Diego, CA.

Miyamoto, S. and I.M. Verma. 1995. Rel/NF-kappa B/I kappa B story. Adv. Cancer Res. 66: 255-292.

Miyamoto, S., P.J. Chiao, and I.M. Verma 1994a. Enhanced I kappa $B$ alpha degradation is responsible for constitutive NFkappa B activity in mature murine B-cell lines. Mol. Cell. Biol. 14: 3276-3282.

Miyamoto, S., M. Maki, M.J. Schmitt, M. Hatanaka, and I.M. Verma. 1994b. Tumor necrosis factor alpha-induced phosphorylation of I kappa B alpha is a signal for its degradation but not dissociation from NF-kappa B. Proc. Natl. Acad. Sci. 91: 12740-12744.

Miyamoto, S., M.J. Schmitt, and I.M. Verma. 1994c. Qualitative changes in the subunit composition of kappa B-binding complexes during murine B-cell differentiation. Proc. Natl. Acad. Sci. 91: 5056-5060.

Miyamoto, S., K. Cauley, and I.M. Verma. 1995. Ultraviolet cross-linking of DNA binding proteins. Methods Enzymol. 254: 632-641.

Naumann, M., F.G. Wulczyn, and C. Scheidereit. 1993. The NF-kappa B precursor p105 and the proto-oncogene product $\mathrm{Bcl}-3$ are I kappa $\mathrm{B}$ molecules and control nuclear translocation of NF-kappa B. EMBO I. 12: 213-222.

Neumann, B., A. Luz, K. Pfeffer, and B. Holzmann. 1996. Defective peyer's patch organogenesis in mice lacking the 55$\mathrm{kD}$ receptor for tumor necrosis factor. J. Exp. Med. 184: 259264.

Nolan, G.P., T. Fujita, K. Bhatia, C. Huppi, H.C. Liou, M.L. Scott, and D. Baltimore. 1993. The bcl-3 proto-oncogene encodes a nuclear I kappa B-like molecule that preferentially interacts with NF-kappa B p50 and p52 in a phosphorylationdependent manner. Mol. Cell. Biol. 13: 3557-3566.

Ohno, H., G. Takimoto, and T.W. McKeithan. 1990. The candidate proto-oncogene bcl-3 is related to genes implicated in cell lineage determination and cell cycle control. Cell 60: $991-997$.

Rajewsky, K. 1996. Clonal selection and learning in the anti- 
body system. Nature 381: 751-758.

Robanus Maandag, E.C., M. van der Valk, M. Vlaar, C. Feltkamp, J. O'Brien, M. van Roon, N. van der Lugt, A. Berns, and $H$. te Riele. 1994. Developmental rescue of an embryonic-lethal mutation in the retinoblastoma gene in chimeric mice. $E M B O$ I. 13: 4260-4268.

Schubart, D., A. Rolink, M. Kosco-Vilbois, F. Botteri, and P. Matthias. 1996. B-cell-specific coactivator OBF-1/OCA-B/ Bob1 required for immune response and germinal centre formation. Nature 383: 538-542.

Schwarz, E.M., P. Salgame, and B.R. Bloom. 1993. Molecular regulation of human interleukin 2 and $\mathrm{T}$-cell function by interleukin 4. Proc. Natl. Acad. Sci. 90: 7734-7738.

Schwarz, E.M., D. Van Antwerp, and I.M. Verma. 1996. Constitutive phosphorylation of $\mathrm{IkBa}$ by casein kinase II occurs preferentially at serine 293: requirement for deradation of free IkBa. Mol. Cell. Biol. 16: 3554-3559.

Sha, W.C., H.C. Liou, E.I. Tuomanen, and D. Baltimore. 1995. Targeted disruption of the p50 subunit of NF-kappa B leads to multifocal defects in immune responses. Cell 80:321330.

te Riele, H., E.C. Robanus Maandag, and A. Berns. 1992. Highly efficient gene targeting in embryonic stem cells through homologous recombination with isogenic DNA constructs. Proc. Natl. Acad. Sci. 89: 5128-5132.

Verma, I.M., J.K. Stevenson, E.M. Schwarz, D. Van Antwerp, and S. Miyamoto. 1995. Rel/NF-K B/I к B family: Intimate tales of association and dissociation. Genes \& Dev. 9: 27232735 .

Welh, F., D. Carrasco, S.K. Durham, D.S. Barton, C.A. Rizzo, R. Ryseck, S.A. Lira, and R. Bravo. 1995. Multiorgan inflammation and hematopoietic abnormalities in mice with a targeted disruption of RelB, a member of the NF-kB/Rel family. Cell 80: 331-340.

Wulczyn, F.G., M. Naumann, and C. Scheidereit. 1992. Candidate proto-oncogene bcl-3 encodes a subunit-specific inhibitor of transcription factor NF-kappa B. Nature 358: 597-599.

Xu, J., T.M. Foy, J.D. Laman, E.A. Elliott, J.J. Dunn, T.J. Waldschmidt, J. Elsemore, R.J. Noelle, and R.A. Flavell. 1994. Mice deficient for the CD40 ligand. Immunity 1: 423-431. 


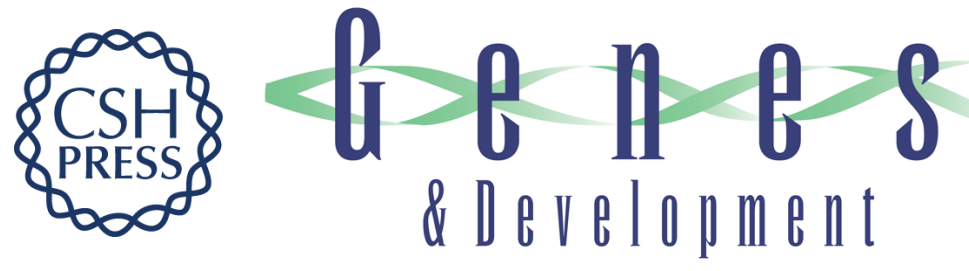

\section{Immunological defects in mice with a targeted disruption in Bcl-3.}

E M Schwarz, P Krimpenfort, A Berns, et al.

Genes Dev. 1997, 11:

Access the most recent version at doi:10.1101/gad.11.2.187 $\begin{array}{ll}\text { References } & \begin{array}{l}\text { This article cites } 42 \text { articles, } 19 \text { of which can be accessed free at: } \\ \text { http://genesdev.cshlp.org/content/11/2/187.full.html\#ref-list-1 }\end{array}\end{array}$

License

Email Alerting

Receive free email alerts when new articles cite this article - sign up in the box at the top Service right corner of the article or click here.

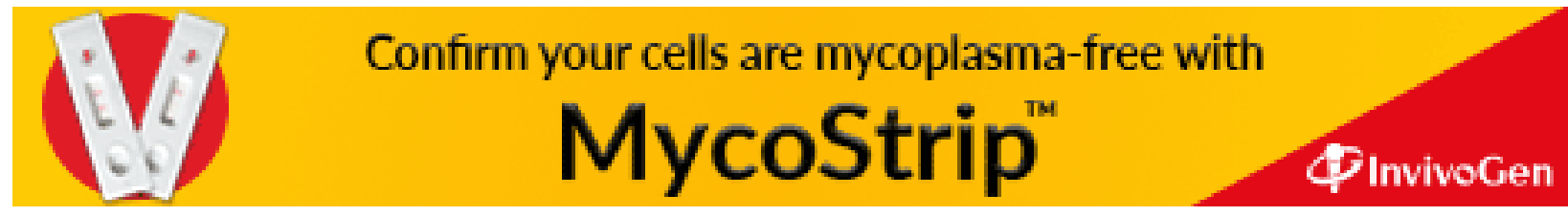

